\title{
Diversity and Functions of Endophytic Fungi Associated with Roots and Leaves of Stipa purpurea in an Alpine Steppe at Qinghai-Tibet Plateau
}

\author{
Xiaoyan Yang ${ }^{1}$, Hui Jin ${ }^{1 *}$, Lihong $\mathrm{Xu}^{2}$, Haiyan Cui ${ }^{3,4}$, Aiyi Xin ${ }^{1}$, Haoyue Liu', and Bo Qin ${ }^{1 *}$ \\ ${ }^{1}$ CAS Key Laboratory of Chemistry of Northwestern Plant Resources and Key Laboratory for Natural Medicine of \\ Gansu Province, Lanzhou Institute of Chemical Physics, Chinese Academy of Sciences, Lanzhou 730000, P.R. China \\ ${ }^{2}$ Qilihe District Agricultural Technology Extension Station of Lanzhou, Lanzhou 730000, P.R. China \\ ${ }^{3}$ School of Forensic Medicine, Shanxi Medical University, Taiyuan 030001, P.R. China \\ ${ }^{4}$ China Institute for Radiation Protection, Taiyuan 030006, P.R. China
}

Stipa purpurea is a unique and dominant herbaceous plant species in the alpine steppe and meadows on the Qinghai-Tibet Plateau (QTP). In this work, we analyzed the composition and diversity of the culturable endophytic fungi in S. purpurea according to morphological and molecular identification. Then, we investigated the bioactivities of these fungi against plant pathogenic fungi and 1aminocyclopropane-1-carboxylate deaminase (ACCD) deaminase activities. A total of 323 fungal isolates were first isolated from S. purpurea, and 33 fungal taxa were identified by internal transcribed spacer primers and grouped into Ascomycota. The diversity of endophytic fungi in $S$. purpurea was significantly higher in roots as compared to leaves. In addition, more than $40 \%$ of the endophytic fungi carried the gene encoding for the ACCD gene. The antibiosis assay demonstrated that $29,35,28,37$ and 34 isolates $(43.9,53.1,42.4,56.1$, and $51.5 \%)$ were antagonistic to five plant pathogenic fungi, respectively. Our study provided the first assessment of the diversity of culturedepending endophytic fungi of S. purpurea, demonstrated the potential application of ACCD activity and antifungal activities with potential benefits to the host plant, and contributed to high biomass production and adaptation of $S$. purpurea to an adverse environment.

Keywords: Endophytic fungi, Stipa purpurea, diversity, ACC deaminase activity, antimicrobial activity

Received: February 28, 2020 Accepted: April 17, 2020

First published online: April 23, 2020

${ }^{*}$ Corresponding authors H.J.

Phone: +86-931-4968372

Fax: +86-931-8277088

E-mail: comefine@126.com B.Q.

E-mail: bqin@ licp.cas.cn

Supplementary data for this paper are available on-line only at http://jmb.or.kr.

pISSN 1017-7825 elSSN 1738-8872

Copyright(C) 2020 by The Korean Society for Microbiology and Biotechnology

\section{Introduction}

With a mean altitude of over 4,000 $\mathrm{m}$, the Qinghai-Tibet Plateau (QTP) is the highest plateau in the world and is sometimes called "the Third Pole of the Earth." It covers approximately 2.5 million $\mathrm{km}^{2}$ and contains glaciers, alpine lakes and waterfalls [1]. There are harsh environmental conditions in the plateau habitat, such as strong wind, high ultraviolet radiation, poor soil nutrient availability, low temperature and precipitation. In such a harsh environment, the dominant vegetation types in the hinterland of the QTP are alpine steppe and alpine meadow, accounting for more than $60 \%$ of the area on the plateau [2]. Alpine steppes and meadows play a very important role in maintaining the living standard of people on the QTP.

Stipa purpurea is a unique and dominant herbaceous plant species in the alpine steppe and meadows on the QTP. It is rich in crude proteins and fats, which makes it an important natural forage resource of major ecological and economic value [3]. The plant has a strong ability to resist alpine environmental stresses, such as strong UV-B radiation, low temperature and drought [4]. As one part of the important alpine ecosystem, S. purpurea plays an important role in preserving and stabilizing diversity in the QTP.

Fungi that live in different organs (root, stem, leaf, flower, fruit, and seed) of a plant without causing visible damage to the host are known as endophytic fungi [5]. Some researchers have shown that the endophytic fungi communities are not only an important source of novel bioactive secondary metabolites, enzymes and biological control agents, but are also important sources of fungi with plant growth-promoting and antimicrobial activities [6-11]. Among these properties, the ability of microbes to produce 1-aminocyclopropane-1-carboxylate deaminase (ACCD) has been identified as one of the direct mechanisms of plant growth promotion. The ACCDproducing plant growth-promoting rhizobacteria (PGPR) not only protect the plant from the negative impact of high ethylene concentration under stress but may also enhance plant growth and development by a number of other mechanisms. These include facilitating nutrient uptake, production of phytohormones, and solubilization of nutrients. There is evidence for the beneficial effect of ACCD-producing PGPR in terms of stress (biotic and 
abiotic) amelioration, biofertilization, biocontrol, phytostimulation and bioremediation, all of which exert a positive impact on crop productivity and normal functioning of the ecosystem $[12,13]$. Interestingly, it has been found that ACCD activity is not unique to bacteria. Evidence of ACCD activity was also detected in Penicillium citrinum and Trichoderma spp. [12,14]. However, the role of ACCD in plant growth-promoting fungi (PGRF) has not been investigated in depth. In addition, many novel and valuable compounds with antimicrobial activity have been successfully obtained from endophytic fungi [15]. Studies have demonstrated that the endophytic fungi community lives in close relation with the plant host, influencing physiological processes and interaction with other organisms. Plant endophytes have been isolated from plants in flooded areas, arctic regions and deserts. It has also been noted that a given plant species can have at least a partially species-specific community of endophytic fungi [16].

At present, most studies of $S$. purpurea have focused on genetic diversity, community classification, physiological ecology and grassland community [1, 17-19]. Based on internal transcribed spacer rRNA cloning and sequencing methods, our previous study has demonstrated that a wide variety of fungal communities were associated with the roots and rhizosphere soil of $S$. purpurea and that the fungal assemblages are strongly influenced by different habitats [20]. Few studies have, however, focused on the diversity of endophytic fungal communities and their potential ecological functions. Therefore, we hypothesized that abundant endophytes associated with the roots and leaves of $S$. purpurea would have functions of PGRF, such as ACCD activity and antimicrobial activity. To test these hypotheses, we collected root and leaf samples of $S$. purpurea at multiple locations in the alpine steppe and meadows on the QTP, analyzed the composition and diversity of culturedependent endophytic communities, and investigated the functional traits of endophytes with potential benefits to the host plant. The aims of this work are i) to characterize endophytic fungi communities found in S. purpurea; ii) to compare the fungal community diversity associated with specific tissues; iii) to determine the functional traits of endophytes with potential benefits to the host plant.

\section{Materials and Methods}

\section{Collection of Samples and Isolation of Fungal Endophytes}

S. purpurea plants were randomly collected in July 2014 from Gangcha steppe district in the Haibei Tibetan Autonomous Prefecture of Qinghai Province $\left(37^{\circ} 16^{\prime}-37^{\circ} 18^{\prime} \mathrm{N}, 100^{\circ} 15^{\prime}-100^{\circ} 18^{\prime} \mathrm{E}\right.$, about 3,265 m a.s.l) where $S$. purpurea is the most dominant plant species. Identification of plants was simple since $S$. purpurea inflorescence was present at sampling time. Some basic properties of the sampling site and the detailed process of the sample collection were described in a previously published study [20]. All plant materials were immediately brought to the laboratory, stored at $4^{\circ} \mathrm{C}$ in a refrigerator and processed within $24 \mathrm{~h}$.

Fresh and healthy green leaves were selected. Roots were selected if they were connected to green leaves, had root hairs, and did not have obvious lesions. The samples were rinsed under running water to remove soil and debris. More than 100 segments were randomly selected for fungal isolations. The segments were surfacesterilized with $75 \%$ ethanol for $30 \mathrm{sec}, 2 \% \mathrm{NaOCl}$ for $10 \mathrm{~min}$ to destroy the surface microbes and their DNA, rinsed three times with distilled water, and then cut into segments $(5-8 \mathrm{~mm})$. Aliquots of the final $\mathrm{H}_{2} \mathrm{O}$ rinse were inoculated on potato dextrose agar (PDA) media (Sigma-Aldrich, USA; containing : $200 \mathrm{~g} / \mathrm{l}$, dextrose $20 \mathrm{~g} / \mathrm{l}$, agar $20 \mathrm{~g} / \mathrm{l} ; \mathrm{pH}$ 6.0), Sigma-Aldrich, USA, containing (g/l): potato 200, dextrose 20 and agar 20; pH 6.0) to verify that no surface microorganisms were present [21]. Around 6 segments of each plant tissue were plated on PDA media containing $50 \mathrm{ppm}$ streptomycin sulfate and $100 \mathrm{ppm}$ ampicillin sodium salt. These antibiotics were used to prevent bacterial growth. The plates were incubated in the dark for 5-7 days at $25^{\circ} \mathrm{C}$. Emerging fungal colonies were recorded, transferred, and purified on PDA plates for 2 or 3 times [22]. All living isolates were preserved in a freezer at $-18^{\circ} \mathrm{C}$ with conservative glycerine in the laboratory.

\section{Molecular Identification}

Microbial DNA was extracted from fungal isolates by using the Plant DNA Extraction Kit (Tiangen Biotech, China) based on the method of Guo et al. [23]. The target regions of ITS rDNA were amplified by PCR $\left(95^{\circ} \mathrm{C}\right.$ for $3 \mathrm{~min}$, followed by $35 \mathrm{cycles}$ of $94^{\circ} \mathrm{C}$ for $30 \mathrm{sec}, 52^{\circ} \mathrm{C}$ for $30 \mathrm{sec}$, and $72^{\circ} \mathrm{C}$ for $30 \mathrm{sec}$, and a final elongation at $72^{\circ} \mathrm{C}$ for $10 \mathrm{~min}$ ) using the following primers: ITS1F (5'-CTT GGT CAT TTA GAG GAA GTA A-3') and ITS4 (5'-TCC TCC GCT TAT TGA TAT GC-3') [24]. PCR was performed in triplicate in mixtures containing $12.5 \mu \mathrm{l}$ $2 \times$ MasterMix (Tiangen Biotech Co., Ltd, China), $0.5 \mu \mathrm{l}$ of each primer $(20 \mu \mathrm{M}$ each), $0.5 \mu$ lemplate, and adding $\mathrm{ddH}_{2} \mathrm{O}$ to a final volume of $25 \mu \mathrm{l}$. Amplifications were performed using a Gene Amp PCR System 9700 (Applied Biosystems, USA). Positive and negative controls (no DNA template) were included in all experiments. The PCR products were tested in $1.2 \%(\mathrm{w} / \mathrm{v})$ agarose gel. Then, the PCR products were purified using a Gel Product Purification Kit (Tiangen Biotech Co., Ltd.) and sequenced by Sangon Biotech Co., Ltd. (Shanghai, China). Fungal isolates were identified by comparison against the SILVA LSU database [25] and a BLASTn search of the nucleotide reference database (http://blast.ncbi.nlm.nih.gov/) [26]. Priority was given to sequences derived from authoritative materials, such as ex-type or ex-epitype cultures. The sequences of the present study were submitted to the NCBI GenBank database.

\section{Diversity Analysis}

Colonization frequency (FC) (\%) was determined as the ratio of the number of plant fragments colonized by fungi and the total number of fragment $\times 100$. Species richness and evenness were calculated by the endophyte diversity analysis. The species diversity was calculated by the methods of Shannon-Wiener, Simpson, and Chao1, while the Pearson product-moment correlation coefficient was used to analyze the possible correlations between 
the root and leaf endophytic fungi communities of $S$. purpurea. To test for the significant differences in the composition of fungal communities from plant tissue environments, we applied Kruskal-Wallis one-way analysis of variance (ANOVA) on ranks. Since the data were not normally distributed, nonparametric tests were used. All statistical analyses were done using Sigma Plot 12.5 (Systat Software, USA) and p values of less than 0.05 were considered to indicate statistical significance. The communities of the endophytic fungi in S. purpurea leaves and roots were related in the ordination of a correspondence analysis (USA). The data were assessed by SPSS 16 software (SPSS, USA).

\section{Functional Traits of Endophytes with Potential Benefits to the Host Plant}

PCR screening of genes for ACC deamination and evaluation of ACCD activity. The acdS gene coding the ACCD was amplified from genomic DNA by specific PCR. The PCR-detection of acdS was PCR-amplified using the primers acdS3F (5'-ATC GGC GGC ATC CAG WSN AAY CAN AC-3') and acdS3R (5'-GTG CAT CGA CTT GCC CTC RTA NAC NGG RT-3'). The PCR mixture had a final volume of $25 \mu \mathrm{l}$, as described above. Amplification conditions were: $4 \mathrm{~min}$ at $94^{\circ} \mathrm{C}, 35 \mathrm{cycles}$ of $45 \mathrm{sec}$ at $94^{\circ} \mathrm{C}, 45 \mathrm{sec}$ at $52,45 \mathrm{sec}$ at $72^{\circ} \mathrm{C}$ and a final extension of $5 \mathrm{~min}$ at $72^{\circ} \mathrm{C}$ [27]. Amplified products were detected by $1.2 \%(\mathrm{w} / \mathrm{v})$ agarose gel electrophoresis. According to the method of Viterbo et al. [12], ACCD activity was evaluated quantitatively by measuring the amount of $\alpha$-ketobutyrate produced by the deamination of ACC. ACCD activity was expressed in $\mu$ mol of $\alpha$ ketobutyrate $/ \mathrm{mg}^{-1}$ of protein $/ \mathrm{h}^{-1}$. Protein concentrations were determined using the Bio-Rad (Promega) reagent. Three independent replicate flasks were analyzed. The experiment was repeated three times.

Antagonistic assay in vitro against pathogenic fungi. All the isolates of fungal endophyte were tested for antagonistic activity against five plant pathogenic fungi: Alternaria alternata [28], Alternaria solani [29], Botrytis cinerea, Fusarium oxysporum [30] and Fusarium solani [31] using the plate diffusion method [32]. All the plant pathogenic fungi were from the CAS Key Laboratory of Chemistry of Northwestern Plant Resources, Lanzhou Institute of Chemical Physics, Chinese Academy of Sciences [33]. The fungal isolates and fungal pathogens were co-cultured on a PDA plate. Briefly, $5 \mathrm{~mm}$ PDA block with 5-day-old mycelia of the pathogenic fungi was placed at the center of a $9 \mathrm{~cm}$ petri plate containing PDA and the isolates of fungal endophyte placed on the agar surface at 3 equidistant points, $2.5 \mathrm{~cm}$ from the periphery of the plate [32]. Dual cultures were incubated at $25^{\circ} \mathrm{C}$ for 5 days and the diameter of fungal mycelial growth was measured and compared to the control (with pathogenic fungi alone).

Table 1. List of identified isolates, their abundances, origin and the frequency of colonization (FC\%).

\begin{tabular}{|c|c|c|c|}
\hline \multirow{2}{*}{ Species name } & \multicolumn{2}{|c|}{ Numbers of isolates and their origin } & \multirow{2}{*}{$\mathrm{FC}(\%)$} \\
\hline & Root & Leaf & \\
\hline Alternaria carthami & 0 & 2 & 0.62 \\
\hline Darksidea delta & 5 & 0 & 1.55 \\
\hline Paraphoma sp. & 3 & 0 & 0.93 \\
\hline Pleosporales sp. & 1 & 0 & 0.31 \\
\hline Saccharicola bicolor & 58 & 0 & 17.96 \\
\hline Stagonospora perfecta & 2 & 0 & 0.62 \\
\hline Phialophora mustea & 9 & 0 & 2.79 \\
\hline Cadophora sp. & 3 & 0 & 0.93 \\
\hline Gloeotinia sp. & 0 & 5 & 1.55 \\
\hline Helotiales sp. & 1 & 0 & 0.31 \\
\hline Scytalidium sp. & 3 & 0 & 0.93 \\
\hline Heydenia alpina & 0 & 2 & 0.62 \\
\hline Heydenia arietina & 0 & 18 & 5.57 \\
\hline Heydenia myrsines & 0 & 14 & 4.33 \\
\hline Fusarium acuminatum & 0 & 4 & 1.24 \\
\hline Fusarium pseudograminearum & 0 & 1 & 0.31 \\
\hline Fusarium tricinctum & 25 & 5 & 9.29 \\
\hline Fusarium sp.1 & 59 & 0 & 18.27 \\
\hline Fusarium sp.2 & 0 & 3 & 0.93 \\
\hline Myrothecium inundatum & 1 & 0 & 0.31 \\
\hline Stachybotrys bisbyi & 3 & 0 & 0.93 \\
\hline Simplicillium chinense & 0 & 2 & 0.62 \\
\hline Trichoderma citrinum & 3 & 0 & 0.93 \\
\hline Trichoderma sp. & 3 & 0 & 0.93 \\
\hline Verticillium leptobactrum & 10 & 0 & 3.10 \\
\hline Verticillium sp. & 23 & 0 & 7.12 \\
\hline Pyricularia ctenantheicola & 1 & 0 & 0.31 \\
\hline Slopeiomyces cylindrosporus & 1 & 0 & 0.31 \\
\hline Chaetomium murorum & 0 & 9 & 2.79 \\
\hline Monosporascus ibericus & 1 & 0 & 0.31 \\
\hline Thielavia hyalocarpa & 0 & 5 & 1.55 \\
\hline Microdochium bolleyi & 37 & 0 & 11.46 \\
\hline Ascomycota sp. & 0 & 1 & 0.31 \\
\hline
\end{tabular}


Each inhibition assay was performed in triplicates, and values were presented as the mean ( \pm standard deviation). The growth inhibition rate was calculated by measuring the inhibition zone diameter, and the formula is as follows:

Growth Inhibition rate $(\mathrm{GI})(\%)=\left(\mathrm{F}_{\mathrm{cd}}-\mathrm{T}_{\mathrm{cd}}\right) /\left(\mathrm{F}_{\mathrm{cd}}-\mathrm{F}_{\mathrm{o}}\right) \times 100$

where $\mathrm{F}_{c d}$ is the fungal colony diameter on the control PDA plate, $\mathrm{T}_{c \mathrm{c}}$ is the fungal colony diameter on the experimental PDA base plate, and $\mathrm{F}_{\mathrm{o}}$ is the diameter of the test fungus agar disks $(5 \mathrm{~mm})$. The growth inhibition of the five pathogenic fungi by the endophytic fungi was assessed by in SPSS 16 software (SPSS).

\section{Results}

Isolates, Sequence Data, Diversity and Abundance

A total of 323 fungal isolates were obtained from the different tissues of S. purpurea. These isolates were grouped into at least 33 fungal taxa (Table 1). The majority of ITS sequences from the fungal isolates did not show complete sequence identity with sequences present in GenBank, ranging from $0.2 \%$ to greater than $10 \%$ sequence variation. All the ITS sequences were deposited in GenBank, and the accession numbers are MK102637-MK102702 corresponding to individual isolates (Table S1).

Further classification by morphological and molecular techniques indicated the dominance of Ascomycota in S. purpurea root and leaf communities. The 33 taxa were classified into 8 orders and 5 classes, with the isolate numbers shown in Fig. S1. Hypocreales was by far the most frequent order, which comprised $47.89 \%$ of the isolate. Most Hypocreales corresponded to Fusarium and Trichoderma. The other fungal orders included Pleosporales, Chaetothyriales, Helotiales, Pezizales, Magnaporthales, Sordariales and Xylariales (Fig. S1 A, 21B and Table S2).

The most abundant 5 of 33 taxa were Fusarium sp. X, Saccharicola bicolor, Microdochium bolleyi, Fusarium sp. Y and Verticillium sp. These 5 taxa accounted for about $64 \%$ of the total isolate numbers (Fig. 1, Table S2). The isolates represented 5 classes at the class level. The class with the most abundant isolate numbers (IN) and strain types (ST) were Sordariomycetes (IN: 196, ST: 39), Dothideomycetes 71 (IN: 71, ST: 17), Pezizomycetes (IN: 34, ST: 4) Eurotiomycetes (IN: 9, ST: 1) and Leotiomycetes (IN: 12, ST: 5) (Figs. S1C and S1D, Table S2).

\section{The Fungal Community Diversity Associated with Specific Tissues}

We found 252 isolates in root and 71 in leaf tissues (Tables 3 and S3). The root community consisted of at least 21 taxa. The leaf community was composed of 13 different taxa (Fig. 1). The diversity indices of these fungal endophytic communities showed relatively high diversity in richness, diversity, evenness, and species coverage (Table 3). Good's coverage ranged from $97.1 \%$ to $97.6 \%$ of the total number of taxa. This indicated that most fungal ITS sequences detected were present in S. purpurea leaves. Root tissues had higher endophytic fungal species

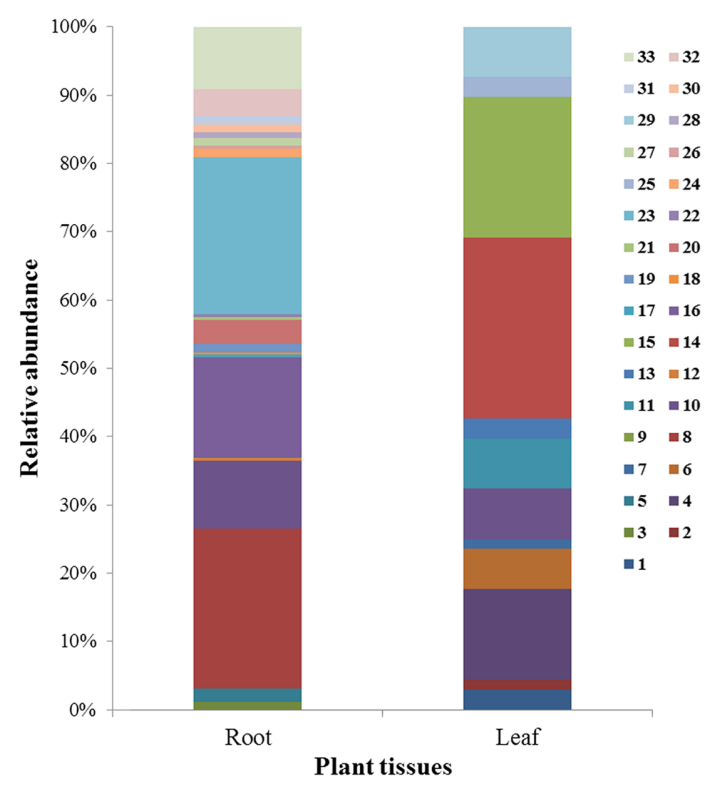

Fig.1. Relative abundance of fungal operational taxonomic units (OUTs) associated with $S$. purpurea with respect to the affiliation at the species level. 1, Alternaria carthami; 2, Ascomycota sp. ; 3, Cadophora sp.; 4, Chaetomium murorum; 5, Darksidea delta; 6, Fusarium acuminatum; 7, Fusarium pseudograminearum; 8, Fusarium sp.1; 9, Fusarium sp.2; 10, Fusarium tricinctum; 11, Gloeotinia sp.; 12, Helotiales sp.; 13, Heydenia alpina; 14, Heydenia arietina; 15, Heydenia myrsines; 16, Microdochium bolleyi; 17, Monosporascus ibericus; 18, Myrothecium inundatum; 19, Paraphoma sp.; 20, Phialophora mustea; 21, Pleosporales sp.; 22, Pyricularia ctenantheicola; 23, Saccharicola bicolor; 24, Scytalidium sp.; 25, Simplicillium chinense; 26, Slopeiomyces cylindrosporus; 27, Stachybotrys bisbyi; 28, Stagonospora perfecta; 29, Thielavia hyalocarpa; 30, Trichoderma citrinum; 31, Trichoderma sp. ; 32, Verticillium leptobactrum; 33, Verticillium sp. 


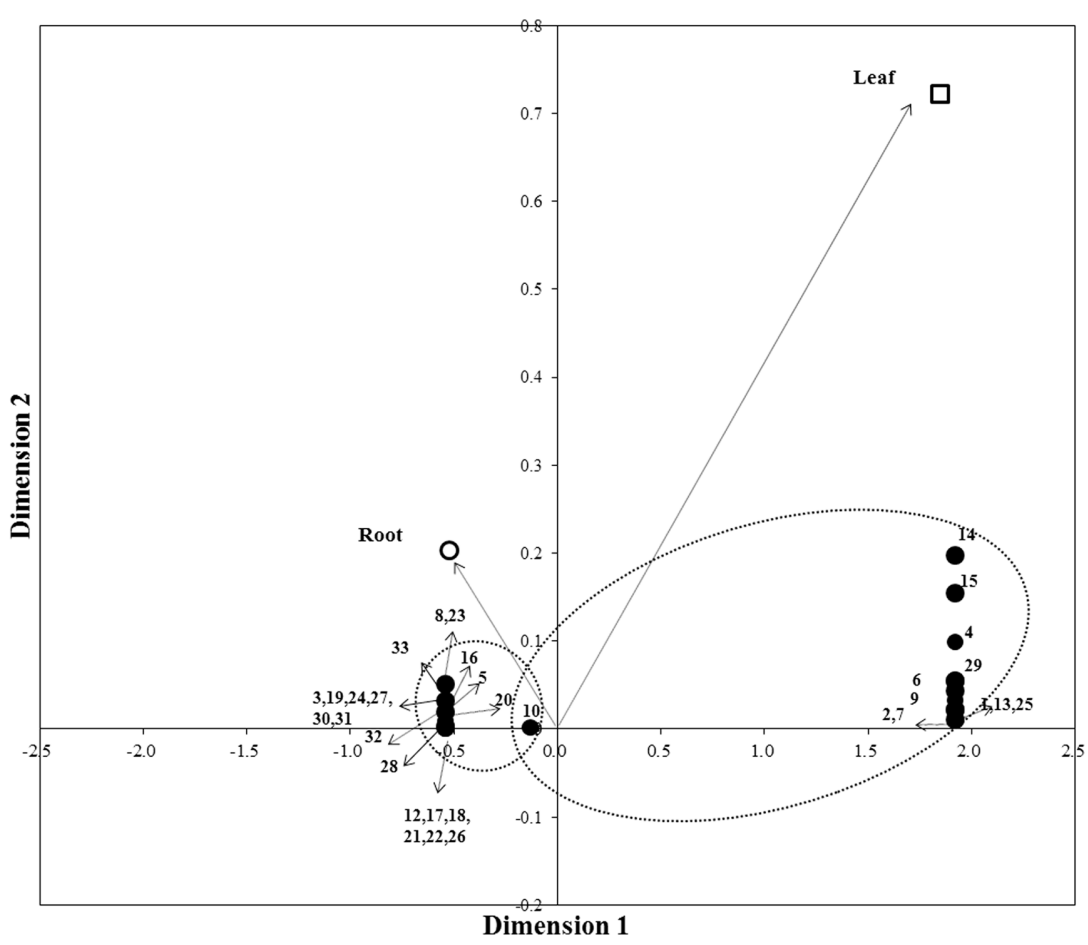

Fig. 2. Correspondence analysis (CA) of the fungal community composition associated with $S$. purpurea. Two different clusters of samples are clearly shown in the CA diagram. Results for roots are clustered at the upper left $(x,-0.521$ $; y, 0.203)$ and results for leaves are at the upper right $(x, 1.847 ; y, 0.722)$. Axes are correspondence components, DIM 1 and DIM2, with score and loading values. 1, Alternaria carthami; 2, Ascomycota sp.; 3, Cadophora sp.; 4, Chaetomium murorum; 5 , Darksidea delta; 6, Fusarium acuminatum; 7, Fusarium pseudograminearum; 8, Fusarium sp.1; 9, Fusarium sp.2; 10, Fusarium tricinctum; 11, Gloeotinia sp.; 12, Helotiales sp.; 13, Heydenia alpina; 14, Heydenia arietina; 15, Heydenia myrsines; 16, Microdochium bolleyi; 17, Monosporascus ibericus; 18, Myrothecium inundatum; 19, Paraphoma sp.; 20, Phialophora mustea; 21 , Pleosporales sp.; 22, Pyricularia ctenantheicola; 23, Saccharicola bicolor; 24, Scytalidium sp.; 25, Simplicillium chinense; 26 , Slopeiomyces cylindrosporus; 27, Stachybotrys bisbyi; 28, Stagonospora perfecta; 29, Thielavia hyalocarpa; 30, Trichoderma citrinum; 31, Trichoderma sp. ; 32, Verticillium leptobactrum; 33, Verticillium sp.

richness and diversity than leaf tissues (Table S3). Out of all the 33 taxa, only one taxon (Fusarium sp. Y) was isolated from both tissues. The most abundant taxa were Fusarium sp. in the roots and Heydenia arietina in the leaves.

The differences of species composition among plant tissue environments were examined using the KruskalWallis ANOVA on ranks (Table S3). We tested the effect of plant tissue environments (total vs. root, total vs. leaf and root vs. leaf) on species composition. The results manifested that there was not a statistically significant difference of fungal endophytic species composition in root and as compared to leaf samples $(p>0.05)$. Furthermore, Pearson's product-moment correlation coefficient indicated the species composition of total endophytic fungi had a positive relationship with the root samples $(p<0.0001)$, but no significant correlation to the leaf samples $(p>0.05)$. Endophytic fungi species composition did not show a significant correlation between the root and leaf samples $(p>0.05)$ (Table S3).

CA was performed to analyze whether certain fungal species were related to a specific plant tissue environment (root or leaf). Differences in the fungal communities associated with the roots and leaves of $S$. purpurea were apparent (Fig. 2). Two cluster samples are clearly shown in the CA diagram. As shown by CA, the fungal community in the root of $S$. purpurea was correlated to sequences assigned to Fusarium sp.1, S. bicolor, M. bolleyi, Fusarium tricinctum, and Verticillium sp.; similarly, the fungal community in the leaf was correlated with sequences assigned to H. arietina, Heydenia myrsines, Chaetomium murorum, and Thielavia hyalocarpa (Fig. 2). $\mathrm{CA}$ also showed that for the 2 compartments, the structure of the fungal communities differed significantly by plant tissue environment: the diversity of the fungal community associated with roots was higher than that with the leaves of $S$. purpurea.

\section{Functional Traits of Endophytes with Potential Benefits to the Host Plant}

As shown in Table 2, a positive PCR amplification of acdS was obtained for 15 isolates ( $42.86 \%$ of the endophytes of S. purpurea) belonging to Paraphoma (1), Saccharicola (1), Cadophora (1), Heydenia (2), Fusarium (1), Simplicillium (1), Trichoderma (2), Slopeiomyces (1), Chaetomium (2), Monosporascus (1), and Microdochium (2). ACCD activity of 15 isolates was determined. All of the 15 isolates exhibited different levels of ACCD activity, 
Table 2. Antifungal activity against five plant pathogenic fungi and ACCD activity of the fungal endophytes from Stipa purpurea.

\begin{tabular}{|c|c|c|c|c|c|c|c|c|}
\hline & & \multicolumn{5}{|c|}{ Fungal growth inhibition* $(\%)$} & \multicolumn{2}{|c|}{ ACCD activity ${ }^{* *}$} \\
\hline Isolates & Identified as & $\begin{array}{l}\text { Botrytis } \\
\text { cinerea }\end{array}$ & $\begin{array}{c}\text { Alternaria } \\
\text { alternata }\end{array}$ & $\begin{array}{c}\text { Alternaria } \\
\text { solani }\end{array}$ & $\begin{array}{l}\text { Fusarium } \\
\text { oxysporum }\end{array}$ & $\begin{array}{c}\text { Fusarium } \\
\text { solani }\end{array}$ & $\begin{array}{l}\mathrm{ACCD} \\
(\operatorname{acdS})\end{array}$ & $\begin{array}{c}\text { ACCD activity } \\
(\mu \mathrm{mol} / \mathrm{mg} \text { per } \\
\text { hour } \\
\text { a-ketobutyrate) }\end{array}$ \\
\hline ZM109 & Alternaria carthami & 0 & 0 & 0 & $6.25 \pm 5.5$ & $34.38 \pm 9.1$ & - & \\
\hline ZMr04 & Paraphoma sp. & $54.1 \pm 5.1$ & $38.9 \pm 6.4$ & $45.7 \pm 7.9$ & $28.6 \pm 7.4$ & $38.2 \pm 11.8$ & + & $0.23 \pm 0.05$ \\
\hline ZMr11 & Paraphoma sp. & $33.3 \pm 6.6$ & $34.7 \pm 5.7$ & $32.9 \pm 7.0$ & 0 & 0 & - & \\
\hline ZMr23 & Pleosporales sp. & 0 & 0 & 0 & $9.4 \pm 5.8$ & $18.8 \pm 6.4$ & - & \\
\hline ZMr02 & Saccharicola bicolor & $6.2 \pm 1.8$ & $40.3 \pm 7.5$ & $34.3 \pm 7.0$ & $26.2 \pm 6.5$ & $54.9 \pm 14.0$ & - & \\
\hline ZMr12 & Saccharicola bicolor & $5.9 \pm 0.2$ & $43.2 \pm 5.8$ & $33.5 \pm 8.3$ & $25.3 \pm 10.4$ & $53.2 \pm 14.8$ & + & $0.43 \pm 0.08$ \\
\hline ZMr20 & Saccharicola bicolor & $6.4 \pm 0.3$ & $39.8 \pm 6.0$ & $32.5 \pm 7.3$ & $23.5 \pm 8.3$ & $52.2 \pm 13.9$ & - & \\
\hline ZMr21 & Saccharicola bicolor & $6.1 \pm 0.1$ & $42.2 \pm 6.2$ & $35.7 \pm 10.0$ & $29.9 \pm 7.9$ & $56.7 \pm 14.3$ & - & \\
\hline ZMr24 & Saccharicola bicolor & $5.9 \pm 0.1$ & $42.5 \pm 7.3$ & $32.1 \pm 7.8$ & $28.7 \pm 8.0$ & $58.8 \pm 15.7$ & - & \\
\hline ZMr29 & Saccharicola bicolor & $5.8 \pm 0.1$ & $44.6 \pm 6.6$ & $33.6 \pm 8.7$ & $23.3 \pm 7.9$ & $55.9 \pm 15.0$ & - & \\
\hline ZMr35 & Saccharicola bicolor & $6.3 \pm 0.2$ & $38.9 \pm 6.7$ & $37.8 \pm 7.1$ & $24.4 \pm 7.9$ & $51.2 \pm 14.2$ & - & \\
\hline ZMr38 & Saccharicola bicolor & $5.7 \pm 0.1$ & $42.3 \pm 7.0$ & $36.7 \pm 7.2$ & $23.5 \pm 8.7$ & $53.2 \pm 13.8$ & - & \\
\hline ZMr48 & Saccharicola bicolor & $6.4 \pm 0.3$ & $43.4 \pm 19.8$ & $35.7 \pm 7.9$ & $25.6 \pm 9.5$ & $56.7 \pm 14.4$ & - & \\
\hline ZMr30 & Stagonospora perfecta & 0 & $20.8 \pm 7.5$ & $28.6 \pm 6.8$ & $16.7 \pm 7.5$ & $42.2 \pm 11.1$ & - & \\
\hline ZMr44 & Stagonospora perfecta & 0 & $21.3 \pm 6.1$ & $29.8 \pm 9.5$ & $15.9 \pm 7.9$ & $43.2 \pm 11.2$ & - & \\
\hline ZMr28 & Phialophora mustea & $2.1 \pm 0.9$ & $18.1 \pm 6.7$ & $28.6 \pm 9.3$ & $9.5 \pm 6.4$ & 0 & - & \\
\hline ZMr40 & Cadophora sp. & $25.0 \pm 1.7$ & $36.1 \pm 8.3$ & $45.7 \pm 7.1$ & $26.2 \pm 8.3$ & 0 & + & $0.27 \pm 0.06$ \\
\hline ZMr33 & Helotiales sp. & 0 & $37.5 \pm 7.5$ & $44.3 \pm 7.2$ & $16.7 \pm 7.9$ & $52.0 \pm 14.7$ & - & \\
\hline ZMl04 & Heydenia alpina & 0 & $30.6 \pm 7.5$ & $38.6 \pm 8.7$ & $21.4 \pm 8.7$ & 0 & + & $0.32 \pm 0.11$ \\
\hline ZMl14 & Heydenia alpina & 0 & $32.3 \pm 6.9$ & $40.9 \pm 7.7$ & $20.1 \pm 9.1$ & 0 & - & \\
\hline ZMl15 & Heydenia arietina & 0 & 0.0 & $42.9 \pm 7.9$ & $28.6 \pm 7.9$ & 0 & + & $0.29 \pm 0.09$ \\
\hline ZMl13 & Heydenia myrsines & 0 & $34.7 \pm 7.9$ & $34.3 \pm 7.3$ & $19.0 \pm 7.4$ & 0 & - & \\
\hline ZMl07 & Fusarium acuminatum & $30.0 \pm 6.6$ & 0 & 0 & $9.4 \pm 7.5$ & $28.1 \pm 8.6$ & - & \\
\hline ZMl17 & $\begin{array}{l}\text { Fusarium } \\
\text { pseudograminearum }\end{array}$ & 0 & $45.8 \pm 7.9$ & $51.4 \pm 8.1$ & $28.6 \pm 9.1$ & $60.8 \pm 15.6$ & - & \\
\hline ZMl10 & Fusarium tricinctum & $35.42 \pm 6.9$ & 0 & $32.9 \pm 7.2$ & 0 & $55.9 \pm 14.7$ & - & \\
\hline ZMl11 & Fusarium tricinctum & $36.6 \pm 6$ & 0 & $30.3 \pm 7.9$ & 0 & $57.7 \pm 16.0$ & - & \\
\hline ZMl12 & Fusarium tricinctum & 0 & 0 & $33.2 \pm 7.5$ & 0 & $52.2 \pm 13.6$ & - & \\
\hline ZMl16 & Fusarium tricinctum & $40.0 \pm 7.6$ & 0 & $35.5 \pm 8.3$ & 0 & $59.5 \pm 14.8$ & - & \\
\hline ZMr01 & Fusarium tricinctum & $52.0 \pm 9.1$ & 0 & $38.6 \pm 8.3$ & $11.9 \pm 7.9$ & $54.9 \pm 13.8$ & - & \\
\hline ZMr14 & Fusarium sp. & $20.8 \pm 6.2$ & 0 & $28.6 \pm 8.3$ & $9.5 \pm 7.8$ & 0 & - & \\
\hline ZMr47 & Fusarium sp. & 0 & $41.7 \pm 8.0$ & $48.6 \pm 8.1$ & $28.6 \pm 7.2$ & $54.9 \pm 14.9$ & - & \\
\hline ZMl03 & Fusarium sp. & $41.7 \pm 7.0$ & $40.3 \pm 8.3$ & $40.0 \pm 8.6$ & $4.8 \pm 5.9$ & $50.0 \pm 13.3$ & + & $1.59 \pm 0.39$ \\
\hline ZMr37 & Myrothecium inundatum & $56.3 \pm 6.2$ & $37.5 \pm 6.9$ & $44.3 \pm 7.2$ & $16.7 \pm 7.5$ & $58.8 \pm 16.2$ & - & \\
\hline ZMl06 & Simplicillium chinense & $25.0 \pm 6.2$ & $25.0 \pm 3.3$ & $44.3 \pm 8.7$ & $11.9 \pm 8.3$ & $57.8 \pm 15.2$ & + & $2.03 \pm 0.58$ \\
\hline ZMr39 & Trichoderma citrinum & 0 & $40.3 \pm 7.5$ & $54.3 \pm 9.7$ & $19.0 \pm 8.3$ & $58.8 \pm 16.2$ & - & \\
\hline ZMr18 & Trichoderma citrinum & 0 & $41.2 \pm 5.4$ & $55.5 \pm 8.3$ & $18.1 \pm 8.7$ & $57.6 \pm 14.5$ & + & $0.63 \pm 0.15$ \\
\hline ZMr19 & Trichoderma sp. & 0 & 0 & 0 & 0 & 0 & + & $0.59 \pm 0.19$ \\
\hline ZMr25 & Verticillium leptobactrum & 0 & 0 & 0 & $6.3 \pm 6.2$ & $35.9 \pm 10.1$ & - & \\
\hline ZMr26 & Verticillium sp. & 0 & $4.5 \pm 5.2$ & 0 & $34.4 \pm 8.9$ & $42.2 \pm 11.5$ & - & \\
\hline ZMr08 & $\begin{array}{l}\text { Slopeiomyces } \\
\text { cylindrosporus }\end{array}$ & $16.6 \pm 5.6$ & $40.3 \pm 7.8$ & $41.4 \pm 8.1$ & $19.0 \pm 9.9$ & $56.9 \pm 14.3$ & + & $7.22 \pm 2.6$ \\
\hline ZMl18 & Chaetomium murorum & 0 & 0 & 0.0 & $14.3 \pm 7.1$ & $59.8 \pm 15.7$ & + & $1.77 \pm 0.65$ \\
\hline ZMl08 & Chaetomium murorum & 0 & 0 & 0.0 & $13.2 \pm 7.9$ & $60.6 \pm 16.1$ & + & $1.63 \pm 0.39$ \\
\hline ZMr17 & Monosporascus ibericus & 0 & $27.8 \pm 7.9$ & $35.7 \pm 7.6$ & $50.0 \pm 7.8$ & $32.4 \pm 8.4$ & + & $0.29 \pm 0.09$ \\
\hline ZMr03 & Microdochium bolleyi & 0 & 0 & 0 & 0 & 0 & + & $0.15 \pm 0.06$ \\
\hline ZMr16 & Microdochium bolleyi & 0 & 0 & 0 & 0 & 0 & + & $0.19 \pm 0.08$ \\
\hline
\end{tabular}

${ }^{*}$ Growth inhibition $96 \mathrm{~h}$ after culture against five plant pathogenic fungi in dual cultures, Results are mean \pm SD of three determinations.

${ }^{*}$ Detection of gene encoding for acdS enzyme ACCD (1-aminocyclopropane-1-carboxylate deaminase), ACCD activity was measured in $\mu \mathrm{mol}$ of $\alpha$-ketobutyrate per milligram of protein per hour. The results are the mean of three replicates.

ranging from 0.15 to $7.22 \mu \mathrm{mol}$ of $\alpha$-ketobutyrate $/ \mathrm{mg}^{-1}$ of protein $/ \mathrm{h}^{-1}$. Among them, Slopeiomyces cylindrosporus ZMr08 showed the highest levels of ACCD activity, with $7.22 \pm 2.6 \mu \mathrm{mol}$ of $\alpha$-ketobutyrate $/ \mathrm{mg}^{-1}$ of protein $/ \mathrm{h}^{-1}$.

The antagonistic activity of the endophytic fungi against the five pathogenic fungi was revealed by inhibition rate between 2.08 and $60.8 \%$. Fusarium pseudograminearum ZMl17 was the strongest antagonist of A. alternata and F. solani, with inhibition zones of $45.8 \%$ and $60.8 \%$, respectively. Alternaria solani was most strongly inhibited by the isolate Trichoderma citrinum $\mathrm{ZMr} 18$, which caused an inhibition zone of $55.5 \%$. The isolate Myrothecium 
Table 3. Comparison of fungal taxa diversity in root and leaf samples by using of Chao 1 richness estimate, Shannon diversity index, Simpson index, Evenness and Coverage.

\begin{tabular}{cccccccc}
\hline Sample & $\begin{array}{c}\text { No. of } \\
\text { isolates }\end{array}$ & $\begin{array}{c}\text { No. of } \\
\text { fungal taxa }\end{array}$ & Chao 1 & Shannon & Simpson & Evenness & Coverage (\%) \\
\hline Root & 252 & 21 & 29.25 & 2.219 & 0.858 & 0.86 & 97.63 \\
Leaf & 71 & 13 & 13.31 & 2.208 & 0.848 & 0.73 & 97.14 \\
\hline
\end{tabular}

The Chao 1, Shannon's diversity, Simpson diversity index, Shannon's evenness and Good's coverage richness estimators were calculated using the species data.

inundatum ZMr37 caused the largest inhibitory zone (56.3\%) in B. cinerea, and Monosporascus ibericus ZMr17, the largest inhibition zone in F. oxysporum (50.0\%).

Among the 33 species, 8 species had antagonistic effects on all the five plant pathogenic fungi. They are: Paraphoma, S. bicolor, Fusarium sp., M. inundatum, Simplicillium chinense, T. citrinum, Verticillium and S. cylindrosporus. F. oxysporum was the most susceptible fungal pathogen.

\section{Discussion}

S. purpurea, as a dominant herbage resource in alpine steppe and meadows, has played an important role in the QTP $[1,3]$. Research and application of endophytic fungi with growth-promoting activity are essential for the sustainable development of the alpine steppe and meadows [20]. To our best knowledge, there is currently no systematic and comprehensive study on the endophytic fungal community of $S$. purpurea and its related functions by culture-dependent methods.

One of the main aims of the study was to assess the diversity of the culturable endophytic fungal community of S. purpurea. Our research showed a wide range of endophytic fungi in S. purpurea leaves and roots (Table S2). Ascomycota dominated in these fungi. The results are similar to those of studies of the endophytic fungal communities of different plants by using culture-independent methods [34, 35]. In contrast, this is not consistent with previous reports of a large number of Basidiomycota endophytes in the root of $S$. purpurea by use of ITS cloning and sequencing [20]. This may be due to the limitation of the method used. Microorganisms are not all culturable [36].

In this study, the dominant endophytic fungal genera of S. purpurea were Fusarium and Trichoderma. These are very common soil fungi and are especially present in the rhizosphere and rhizoplane [37,38]. Fusarium includes many plant, human, and insect pathogens as well as saprobes $[39,40]$ and had been investigated as a model of agriculturally relevant biological control fungi [41]. Fusarium species are common endophytes of Phragmites australis [42], Ilex paraguariensis [40], Panax notoginseng [43] and Glycine max [44]. Trichoderma contains important plant pathogen control agents and antimicrobial compound producers [45]. There are also some special fungal species in the root and leaf of S. purpurea, such as Alternaria carthami, M. inundatum, Pyricularia ctenantheicola, S. cylindrosporus and Monosporascus ibericus. Thus, S. purpurea hosts rich and diversified fungal resources [39]. There is an obvious difference between the occurrence frequencies of $S$. cylindrosporus with that previously reported [46]. This difference might be caused by environmental and abiotic stress. A large number of studies have shown that the environmental conditions of the alpine steppe and meadows in the QTP are relatively harsh $[1,16]$. Therefore, specific isolates of Fusarium, Trichoderma, and some special rare taxa fungal species may be able to grow better under stressful conditions than other fungi, while establishing a more intimate relationship with S. purpurea [22, 38, 41].

Plant tissues are possible habitats for new fungal resources $[5,15]$. Our study showed structural differences in the communities of culturable endophytic fungi colonizing $S$. purpurea leaves and roots with more fungal species in the roots than in the leaves. The dominant endophytic species in the different tissues of the plant also differed $[47,48]$. Fusarium species are highly common endophytes that have been reported in almost all studied host plants. Heydenia species are in the leaf of S. purpurea (Rare taxa $(\mathrm{RF}<1 \%))$ [47]. Heydenia species are found in extreme conditions, such as alpine habitats [49], lakes of maritime Antarctica [50], and soil and moss from the Taylor Valley in south Victoria Land of Antarctica [51]. This fact further confirmed the importance of studying the culturable endophytic fungi of $S$. purpurea under a harsh environment. Our study demonstrates that the endophytic fungi of $S$. purpurea are more abundant and diverse in roots than in leaves. This is consistent with previous research results $[34,42]$. Some studies showed that the roots of perennial plants would have more time to accumulate endophytes from the soil and rhizosphere [52]. The prevalence and diversity of soil-borne fungi is higher than those infecting the aerial parts of the plant $[17,42,48]$. As $S$. purpurea is an excellent pasture plant, overgrazing has brought enormous pressure on the S. purpurea steppe. Since the root was the main place for endophytic fungi to survive, this might be correlated with its presence as the dominant herbage resource in alpine steppe and meadows on the QTP (Table 1).

Data from this study and previous reports revealed that the diversity of the endophytic fungal community in the root of $S$. purpurea was significant when internal transcribed spacer rRNA cloning and sequencing approaches were compared to culture approaches. The endophyte communities show only a $7.5 \%$ overlap in the dominant phyla or species between these two approaches [20]. The culture-dependent approaches are heavily biased towards fast-growing species, and many fungi have specialized growth requirements, so this approach may be biased in favor of the dominant species [36]. The ITS rRNA cloning library approach to a wide range of substrates has resulted in the identification of a large number of new fungal species that cannot be cultivated, many of which constitute novel lineages or are dominant components of microbial communities. Both approaches show that the 
host is a strong diversifier of fungal community structure, but that each alone covers only a small proportion of the real fungal community [53].

The knowledge of the culturable endophytic community composition is of great value for the development of technologies for agricultural management, in particular those related to microorganism-based growth promotion, since the isolates are available for activity and inoculation analyses [40]. In this study, the potential of endophytic isolates for plant growth promotion was determined by ACCD gene detection and fungal antagonism. Given the importance of $S$. purpurea for the alpine steppe and meadows ecosystem, these results will contribute to knowledge for maximizing growth and health of forage. The isolates with ACCD activity are of much concern as PGPF. This enzyme makes use of the ethylene precursor, leading to a reduction in the ethylene concentration of plants and a consequent decrease in its negative effect on plant growth. Thus, the plants can better resist the stress of adverse environmental conditions such as drought, heavy metal, saline-alkali, and the presence of phytopathogens [54]. However, it should be emphasized that the research on ACCD-containing PGPR mainly focuses on the plants that are ethylene sensitive, such as canola, peppers and tomatoes $[13,55]$. Therefore, it is necessary to identify sources of ACCD, such as in various adverse and extreme environmental conditions. $S$. purpurea is the dominant species in alpine arid and semi-arid meadows because of its outstanding tolerance to harsh environments (including cold, drought, and wind). Transcriptome analysis reveals a diversified adaptation of S. purpurea along a drought gradient on the QTP [1]. In our study, almost $40 \%$ of the isolates had the potential to produce ACCD. Species of these genera were also are considered as potential fungal inoculants for ACCD activities $[12,14]$. In previous studies, it was demonstrated that the utilization ability of ACC was the most effective mechanism involved in root elongation and endophytic colonization by the isolates [12, 40]. Therefore, further study on ACCD-producing endophytic fungi of S. purpurea might also effectively reveal their adaptive mechanism under special circumstances and promote the growth of this forage.

In our study, a fairly high percentage (63\%) of the 66 fungal isolates had obvious antagonistic properties, suggesting that the endophytic fungi of $S$. purpurea can resist certain microbial diseases. An increasing number of findings have indicated that new natural products from native grass-associated fungi exhibit antifungal activity [56]. Isolates from Fusarium, Trichoderma, Verticillium, Myrothecium and Simplicillium were found to have high antifungal activities. Although Fusarium as endophytes are normally in latent form but readily attack plants when conditions allow, they are a source of agricultural antibiotics and a biological control agent $[7,38,41]$. Members of the genus Trichoderma and Verticillium are reported as prolific sources for the production of natural products and many possess antifungal activity. So far, Trichoderma spp. are among the most studied fungal-based of biocontrol agents (BCAs) and are commercially marketed as biopesticides, biofertilizers and soil amendments [57]. Simplicillium species, as bio-control agents of phytopathogenic fungi and plant parasitic nematodes, have demonstrated positive effects [58]. These have been isolated mainly from soil [59]. As the alpine steppe and meadows are rarely affected by application of pesticides, this natural habitat contains richness in microbial resources [60]. Therefore, the endophytic fungi isolated from these especially can be one of the sources of plant disease biological control agents. This result is in agreement with previous reports on plants with strong resistance to fungal infection which have become an important source of antagonistic fungi [61].

What makes $S$. purpurea so successful even under apparently harsh environmental conditions has been the subject of much speculation. Our current findings on the cultivable endophytic fungi community composition and diversity and the beneficial traits microbes possess have furnished some evidence on the potential role of these microbes on the forage biomass production and the adaption of $S$. purpurea to adverse environments. The dual activities of microbial inhibition and plant growth promotion found in the endophytic isolates of Fusarium, Trichoderma, Verticillium and Simplicillium may provide S. purpurea with its adaptation to the adverse environment in the alpine steppe of the QTP and lay the foundation for the development of natural germicidal products.

\section{Acknowledgments}

We are grateful to Professor Frank R. Stermitz for editorial assistance. This work was financially supported by the National Key Research and Development Program (2017YFD0200804-05), the National Natural Science Foundation of China (31560037, 31772668, 31570354 and 21775154), Cooperation Program to Gansu Province of Lanzhou Branch of the Chinese Academy of Sciences and CAS "Light of West China" Program.

\section{Conflict of Interest}

The authors have no financial conflicts of interest to declare.

\section{References}

1. Yang YQ, Li X, Kong XX, Ma L, Hu XX, Yang YP. 2015. Transcriptome analysis reveals diversified adaptation of Stipa purpurea, along a drought gradient on the Tibetan plateau. Funct. Integr. Genomics 15: 295-307.

2. Liu WS, Dong M, Song ZP, Wei W. 2009. Genetic diversity pattern of Stipa purpurea populations in the hinterland of Qinghai-Tibet plateau. Ann. Appl. Biol. 154: 57-65.

3. Ma BB, Sun J. 2018. Predicting the distribution of Stipa purpurea across the Tibetan Plateau via the MaxEnt model. BMC Ecol. 18: 10.

4. Zhou YL, Cheng Y, Yang YQ, Li X, Supriyo B, Sun XD. 2016. Overexpression of spcbl6, a calcineurin b-like protein of Stipa purpurea, enhanced cold tolerance and reduced drought tolerance in transgenic Arabidopsis. Mol. Biol. Rep. 43: 657-966.

5. Zheng YK, Qiao XG, Miao CP, Liu K, Chen YW, Xu LH. 2016. Diversity, distribution and biotechnological potential of endophytic fungi. Ann. Microbiol. 66: 529-542.

6. Soliman SSM, Trobacer CP, Tsao R, Greenwood JS, Raizada MN. 2013. A fungal endophyte induces transcription of genes encoding a redundant fungicide pathway in its host plant. BMC Plant Biol. 13: 93. 
7. Chen XM, Dong HL, Hu KX, Sun ZR, Chen J, Guo SX. 2010. Diversity and antimicrobial and plant-growth-promoting activities of endophytic fungi in Dendrobium loddigesii Rolfe. J. Plant Growth Reg. 29: 328-337.

8. Xing YM, Chen J, Cui JL, Chen XM. Guo SX. 2011. Antimicrobial activity and biodiversity of endophytic fungi in Dendrobium devonianum and Dendrobium thyrsiflorum from Vietnam. Curr. Microbiol. 62: 1218-1224.

9. Bezerra JDP, Santos MGS, Svedese VM, Lima DMM, Fernandes MJS, Paiva LM, et al. 2012. Richness of endophytic fungi isolated from Opuntia ficus-indica Mill (Cactaceae) and preliminary screening for enzyme production. World J. Microbiol. Biotechnol. 28:1989-1995.

10. Zhang XY, Bao J, Wang GH, He F, Xu XY. Qi SH. 2012. Diversity and antimicrobial activity of culturable fungi isolated from six species of the South China Sea gorgonians. Microb. Ecol. 64: 617-627.

11. Zhang W, Xu L, Yang L, Huang Y, Li S. Shen Y. 2014c. Phomopsidone A, a novel depsidone metabolite from the mangrove endophytic fungus Phomopsis sp. A123. Fitoterapia 96: 146-151.

12. Viterbo A, Landau U, Kim S, Chernin L, Chet I. 2010. Characterization of ACC deaminase from the biocontrol and plant growthpromoting agent Trichoderma asperellum T203. FEMS Microbiol. Lett. 305: 42-48.

13. Ghosh PK, De TK, Maiti TK. 2018. Role of acc deaminase as a stress ameliorating enzyme of plant growth-promoting rhizobacteria useful in stress agriculture: a review. pp. 57-106. Role of Rhizospheric Microbes in Soil. Springer, Singapore.

14. Jia YJ, Ito H, Matsui H, Honma M. 2000. 1-aminocyclopropane-1-carboxylate (ACC) deaminase induced by ACC synthesized and accumulated in Penicillium citrinum intracellular spaces. Biosci. Biotechnol. Biochem. 64: 299-305.

15. Rai M, Rathod D, Agarkar G, Dar M, Brestic M, Pastore GM, et al. 2014. Fungal growth promotor endophytes: a pragmatic approach towards sustainable food and agriculture. Symbiosis 62: 63-79.

16. Przemieniecki SW, Damszel M, Kurowski TP, Mastalerz J, Kotlarz K. 2019. Identification, ecological evaluation and phylogenetic analysis of non-symbiotic endophytic fungi colonizing timothy grass and perennial ryegrass grown in adjacent plots. Grass Forage Sci. 74: 42-52.

17. Sun J, Peng M, Chen GC, Wang SZ, Zhou GY. 2003. Study on community characteristics and community diversity in Stipa steppe of Qinghai Lake region. Acta Bot. Sin. 23: 1963-1968.

18. Duan MJ, Gao QZ, Wan YF, Yue L, Guo YQ, Luobu D. 2010. Effect of grazing on community characteristics and species diversity of Stipa purpurea alpine grassland in northern Tibet. Acta Ecologica Sin. 30: 3892-3900.

19. Liu WS, Zhao Y, You JL, Qi DH, Zhou Y, Chen JK, et al. 2016. Morphological and genetic variation along a north-to-south transect in Stipa purpurea, a dominant grass on the Qinghai-Tibetan Plateau: implications for response to climate change. PLoS One 11: e0161972.

20. Lu DX, Jin H, Yang XY, Zhang DH, Yan ZQ, Li XZ, et al. 2016. Characterization of rhizosphere and endophytic fungal communities from roots of Stipa purpurea in alpine steppe around Qinghai Lake. Can. J. Microbiol. 62: 643-656.

21. Ye X, Seth DB, Jamin D, Delia S, Williams M. 2015. Characterization of culturable bacterial endophytes and their capacity to promote plant growth from plants grown using organic or conventional practices. Front. Plant Sci. 6: 490.

22. Ghimire SR, Charlton ND, Bell JD, Krishnamurthy YL, Craven KD. 2011. Biodiversity of fungal endophyte communities inhabiting switch grass (Panicum virgatum L.) growing in the native tallgrass prairie of northern Oklahoma. Fungal Divers. 47: 19-27.

23. Guo LD, Hyde KD, Liew ECY. 2000. Identification of endophytic fungi from Livistona chinensis based on morphology and rDNA sequences. New Phytol. 147: 617-630.

24. Gardes M, Bruns TD. 1993. ITS primers with enhanced specificity for basidiomycetes-application to the identification of mycorrhizae and rusts. Mol. Ecol. 2: 113-118.

25. Altschul SF, Madden TL, Schaffer AA, Zhang J, Zhang Z, Miller W, et al. 1997. Gapped BLAST and PSIBLAST: a new generation of protein database search programs. Nucleic Acids Res. 25: 3389-3402.

26. Zhang Z, Schwartz S, Wagner L, Miller W. 2000. A greedy algorithm for aligning dna sequences. J. Comput. Biol. 7: $203-214$.

27. Li ZY. 2011. High-throughput screening and identification of bacteria containing ACC deaminase, M.S. Thesis of Zhejiang University. Hangzhou.

28. Tsuge T, Harimoto Y, Akimitsu K, Ohtani K, Kodama M, Akagi Y, et al. 2013. Host-selective toxins produced by the plant pathogenic fungus Alternaria alternata. FEMS Microbiol. Rev. 37: 44-66.

29. Abuley IK, Nielsen BJ, Labouriau R. 2018. Resistance status of cultivated potatoes to early blight (Alternaria solani) in denmark. Plant Pathol. 67: 315-326.

30. Dean R, Van Kan JAL, Pretorius ZA, Pietro AD, Spanu PD, Rudd JJ, et al. 2012. The top 10 fungal pathogens in molecular plant pathology. Mol. Plant Pathol. 13: 804-804.

31. Aoki T, O’Donnell Kerry, Geiser DM. 2014. Systematics of key phytopathogenic Fusarium species: current status and future challenges. J. Gen. Plant Pathol. 80: 189-201.

32. Mohamad OA, Li L, Ma JB, Hatab S, Xu L, Guo J W, et al. 2018. Evaluation of the Antimicrobial activity of endophytic bacterial populations from Chinese traditional medicinal plant licorice and characterization of the bioactive secondary metabolites produced by Bacillus atrophaeus against Verticillium dahliae. Front. Microbiol. 9: 924.

33. Pan L, Li XZ, Jin H, Yang XY, Qin B. 2017. Antifungal activity of umbelliferone derivatives: synthesis and structure-activity relationships. Microb. Pathogenesis 104: 110-115.

34. Jin H, Yang XY, Lu DX, Li CJ, Yan ZQ, Li XZ, et al. 2015. Phylogenic diversity and tissue specificity of fungal endophytes associated with the pharmaceutical plant, Stellera chamaejasme L. revealed by a cultivation-independent approach. Antonie Van Leeuwenhoek 108: $835-850$.

35. Wang Y, Lai Z, Li XX, Yan R, Zhang ZB, Yang H. 2016. Isolation, diversity and acetylcholinesterase inhibitory activity of the culturable endophytic fungi harboured in Huperzia serrata from Jinggang Mountain, China. World J. Microbiol. Biotechnol. 32: 20.

36. Hyde KD, Soytong K. 2008. The fungal endophyte dilemma. Fungal Divers. 163: e173.

37. Zhang FL, Ge HL, Zhang F, Guo N, Wang YC, Chen L, et al. 2016. Biocontrol potential of Trichoderma harzianum isolate T-aloe against Sclerotinia sclerotiorum in soybean. Plant Physiol. Biochem. 100: 64-74.

38. da Silva CF, Vitorino LC, Soares MA, Souchie EL. 2018. Multifunctional potential of endophytic and rhizospheric microbial isolates associated with Butia purpurascens roots for promoting plant growth. Antonie Van Leeuwenhoek 111: 1-18.

39. Zabalgogeazcoa I, Gundel PE, Helander M, Saikkonen K. 2013. Nonsystemic fungal endophytes in Festuca rubra plants infected by Epichloë festucae in subarctic habitats. Fungal Divers. 60: 25-32.

40. Pérez ML, Collavino MM, Sansberro PA, Mroginski LA, Galdeano E. 2016 Diversity of endophytic fungal and bacterial communities in Ilex paraguariensis grown under field conditions. World J. Microbiol. Biotechnol. 32: 61.

41. Kepler RM, Maul JE, Rehner SA. 2017. Managing the plant microbiome for biocontrol fungi: examples from Hypocreales. Curr. Opin. Microbiol. 37: 48-53.

42. Angelini P, Rubini A, Gigante D, Reale L, Pagiotti R, Venanzoni R. 2012. The endophytic fungal communities associated with the leaves and roots of the common reed (Phragmites australis) in Lake Trasimeno (Perugia, Italy) in declining and healthy stands. Fungal Ecol. 5: 683-693.

43. Sun WJ, Zhu HT, Zhang TY, Zhang MY, Wang D, Yang CR, et al. 2018. Two New Alkaloids from Fusarium tricinctum SYPF 7082, an Endophyte from the Root of Panax notoginseng. Nat. Prod. Bioprospect. 8: 391-396. 
44. Yang HJ, Ye WW, Ma JX, Zeng DD, Rong ZY, Xu M, et al. 2018. Endophytic fungal communities associated with field-grown soybean roots and seeds in the Huang-Huai region of China. PeerJ. 6: e4713.

45. Bae SJ, Mohanta TK, Chung JY, Ryu M, Park G, Shim S, et al. 2016. Trichoderma metabolites as biological control agents against Phytophthora pathogens. Biol. Control 92: 128-138.

46. Pereira EC, Vazquez-de-Aldana B, San Emeterio L, Zabalgogeazcoa I. 2019. A survey of culturable fungal endophytes from Festuca rubra subsp. pruinosa, a grass from marine cliffs, reveals a core microbiome. Front. Microbiol. 9: 3321

47. Zang W, Sun X, Sun JQ, Yu WX, Wang XS, Yin JX, et al. 2014. Diversity and community structure of endophytic fungi from Taxus chinensis var. mairei. Chinese J. Appl. Ecol. 25: 2071-2078.

48. Xia Y, Amna A, Opiyo SO. 2018. The culturable endophytic fungal communities of switchgrass grown on a coal-mining site and their effects on plant growth. PLoS One 13: e0198994.

49. Leuchtmann A, Clémençon H. 2012. The taxonomic position of the genus Heydenia (Pyronemataceae, Pezizales) based on molecular and morphological data. Mycol. Prog. 11: 699-710.

50. Gonçalves VN, Vaz AB, Rosa CA, Rosa LH. 2012. Diversity and distribution of fungal communities in lakes of Antarctica. FEMS Microbiol. Ecol. 82: 459-471.

51. Slemmons C, Johnson G, Connell LB. 2013. Application of an automated ribosomal intergenic spacer analysis database for identification of cultured Antarctic fungi. Antarct. Sci. 25: 44-50.

52. Su YY, Guo LD, Hyde KD. 2010. Response of endophytic fungi of Stipa grandis to experimental plant function group removal in Inner Mongolia steppe. China. Fungal Divers. 43: 93-101.

53. O’Brien HE, Parrent JL, Jackson JA, Moncalvo JM, Vilgalys R. 2005. Fungal community analysis by large-scale sequencing of environmental samples. Appl. Environ. Microbiol. 71: 5544-5550.

54. Glick BR, Todorovic B, Czarny J, Cheng Z, Duan J, McConkey B. 2007. Promotion of plant growth by bacterial ACC deaminase. Crit. Rev. Plant Sci. 26: 227-242.

55. Penrose DM, Glick BR. 2003. Methods for isolating and characterizing ACC deaminase-containing plant growth promoting rhizobacteria. Physiol. Plant 118: 10-15.

56. Niones JT, Takemoto D. 2014. An isolate of Epichloë festucae, an endophytic fungus of temperate grasses, has growth inhibitory activity against selected grass pathogens. J. Gen. Plant Pathol. 80: 337-347.

57. Vinale F, Sivasithamparam K, Ghisalberti EL, Marra R, Woo SL, Lorito M. 2008. Trichoderma-plant-pathogen interactions. Soil Biol. Biochem. 40: 1-10.

58. Gomes AA, Pinho DB, Cardeal ZDL, Menezes HC, DeQueiroz MV, Pereira OL. 2018. Simplicillium coffeanum, a new endophytic species from Brazilian coffee plants, emitting antimicrobial volatiles. Phytotaxa 333: 188-198.

59. Nonaka K, Kaifuchib S, Ômuraa S, Masuma R. 2013. Five new Simplicillium species (Cordycipitaceae) from soils in Tokyo, Japan. Mycoscience 54: 42-53.

60. Li ZD, Chen XR, Li P. 2011. Screening and identification of endophytic bacteria from Stipa purpurea. Grassland and Turf. 31: 8-12.

61. Zhang HT, Yu PP, Abudula H, Xu TM, Mijit G. 2007. Characterstics and identification of an antagonistisc XJUL-6 against cotton verticillium wilt. Acta Microbiol. Sin. 47: 1084-1087. 